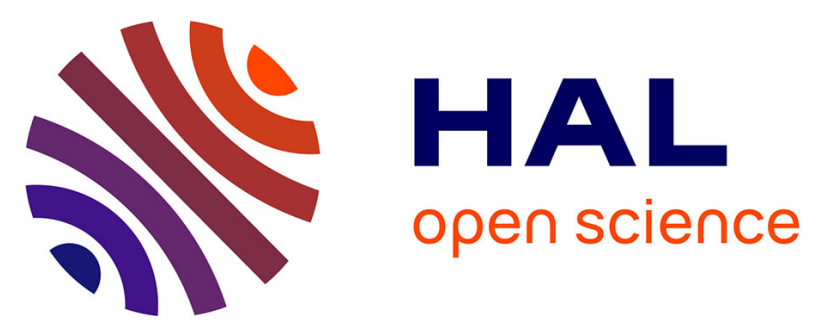

\title{
No pol mutation is associated independently with the lack of immune recovery in patients infected with HIV and failing antiretroviral therapy
}

\author{
Nicola Gianotti, Laura Galli, Maurizio Zazzi, Valeria Ghisetti, Stefano \\ Bonora, Valeria Micheli, Paola Meraviglia, Paola Corsi, Bianca Bruzzone, \\ Stefano Menzo, et al.
}

\section{To cite this version:}

Nicola Gianotti, Laura Galli, Maurizio Zazzi, Valeria Ghisetti, Stefano Bonora, et al.. No pol mutation is associated independently with the lack of immune recovery in patients infected with HIV and failing antiretroviral therapy. Journal of Medical Virology, 2011, 83 (3), pp.391. 10.1002/jmv.21989 . hal00610729

\author{
HAL Id: hal-00610729 \\ https://hal.science/hal-00610729
}

Submitted on 24 Jul 2011

HAL is a multi-disciplinary open access archive for the deposit and dissemination of scientific research documents, whether they are published or not. The documents may come from teaching and research institutions in France or abroad, or from public or private research centers.
L'archive ouverte pluridisciplinaire HAL, est destinée au dépôt et à la diffusion de documents scientifiques de niveau recherche, publiés ou non, émanant des établissements d'enseignement et de recherche français ou étrangers, des laboratoires publics ou privés. 


\section{Journal of Medical Virology}

WILEY

\section{No pol mutation is associated independently with the lack of immune recovery in patients infected with $\mathrm{HIV}$ and failing antiretroviral therapy}

\begin{tabular}{|c|c|}
\hline Journal: & Journal of Medical Virology \\
\hline Manuscript ID: & JMV-10-1971.R1 \\
\hline Wiley - Manuscript type: & Research Article \\
\hline $\begin{array}{r}\text { Date Submitted by the } \\
\text { Author: }\end{array}$ & 27-Sep-2010 \\
\hline Complete List of Authors: & $\begin{array}{l}\text { Gianotti, Nicola; Ospedale San Raffaele, Divisione di Malattie } \\
\text { Infettive } \\
\text { Galli, Laura; San Raffaele Scientific Institute, Infectious Diseases } \\
\text { Zazzi, Maurizio; University of Siena, Molecular Biology } \\
\text { Ghisetti, Valeria; Ospedale Amedeo di Savoia, Microbiology \& } \\
\text { Virology Laboratory } \\
\text { bonora, stefano; university of Torino, infectiuos diseases } \\
\text { Micheli, Valeria; Ospedale L. Sacco, Microbiology Laboratory } \\
\text { Meraviglia, Paola; Ospedale L. Sacco, Second Division of Infectious } \\
\text { Diseases } \\
\text { Corsi, Paola; Ospedale Careggi, Division of Infectious Diseases } \\
\text { Bruzzone, Bianca; Ospedale San Martino, Health Laboratory } \\
\text { Menzo, Stefano; Ospedale di Ancona, Virology Laboratory } \\
\text { Di Giambenedetto, Simona; Sacro Cuore Catholic University, } \\
\text { Institute of Infectious Diseases } \\
\text { De Luca, Andrea; Sacro Cuore Catholic University, Institute of } \\
\text { Infectious Diseases; University Hospital of Siena, Infectious } \\
\text { Diseases Unit } \\
\text { Filice, Gaetano; Policlinico San Matteo, Infectious and Tropical } \\
\text { Diseases Clinic } \\
\text { Penco, Giovanni; Ospedali Galliera, Infectious Diseases } \\
\text { Castagna, Antonella; San Raffaele Scientific Institute, Infectious } \\
\text { Diseases }\end{array}$ \\
\hline Keywords: & $\begin{array}{l}\text { CD4 T-lymphocytes, drug resistance, resistance to protease } \\
\text { inhibitors, resistance to nucleoside reverse transcriptase inhibitors, } \\
\text { resistance to non-nucleoside reverse transcriptase inhibitors }\end{array}$ \\
\hline
\end{tabular}




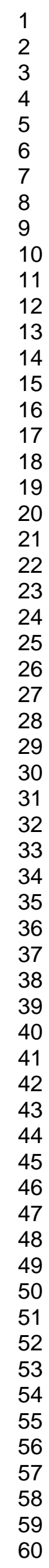

\section{SCHOLARONE" \\ Manuscripts}

14

15

16

18

19

20

22

23

25

26

27

29

32

33

34

36

37

38

41

42

43
44

45

46

47

48

50

51

52

53

54

56

57

58

69

John Wiley \& Sons 
Table I. Demographic and clinical characteristics of the study subjects

\begin{tabular}{|c|c|c|c|}
\hline Overall & Lack of immune & Immune & \\
\hline$(n=826)$ & recovery & recovery & $P$ value \\
\hline & $(n=375)$ & $(n=451)$ & \\
\hline
\end{tabular}

\section{Demographic and clinical characteristics at baseline}

Gender, $n$ (\%)

Male

Female

Median age at baseline, years (Q1, Q3)

AIDS diagnosis before baseline, $n(\%)$
$577(69.8)$

$249(30.2)$

$40(37,45)$

24 (2.9)

Median duration of antiretroviral

treatment, years $(Q 1, Q 3)$

Median baseline CD4+ count,

cells $/ \mathrm{mm}^{3}(\mathrm{Q1}, \mathrm{Q3})$

Median baseline HIV-RNA, $\log _{10}$

copies/ml (Q1, Q3)

\author{
$4.5(3.7,5.5)$ \\ $4.4(3.6,5.4)$ \\ $4.5(3.7,5.6)$ \\ 0.623 \\ $358(211,524)$ \\ $418(257,593)$ \\ $310(195,454) \quad<0.0001$ \\ $3.9(3.4,4.5)$ \\ $3.9(3.3,4.6)$ \\ $3.9(3.4,4.5)$ \\ 0.552
}

\section{Genotype characteristics at baseline}

Year of genotyping, $n(\%)$

$$
2000
$$

107 (3.0)

2001

175 (21.2)

2002

$157(19.0)$

$387(46.9)$

Median total number of mutations (Q1,

$7(4,10)$

Q3)

Presence of at least 1 NRTI mutation, $n$

(\%)

$711(86.1)$

$328(87.5)$

383 (84.9)

0.314

Median number of TAMs (Q1, Q3)

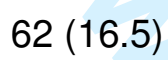

$88(23.5)$

72 (19.2)

$153(40.8)$

$7(4,11)$
$2(0,4)$

0.392 
Presence of at least 1 TAM, $n(\%)$

$614(74.3)$

TAMs, $n$ (\%)
$284(75.7)$

$330(73.2)$

0.424

\section{Follow-up characteristics}

Median years of follow-up (Q1, Q3)

\section{$3.1(3.1,3.3)$}

Median 3-year HIV-RNA, $\log _{10}$

copies/ml (Q1, Q3)

Median change in HIV-RNA, $\log _{10}$

copies/ml (Q1, Q3)

Median viremia detectability ratio (Q1,

$$
\begin{gathered}
444(53.8) \\
1(0,2)
\end{gathered}
$$

$460(55.7)$

$7(5.5,8)$

$3(1,3)$

$5(3,5)$
91 (24.3)

$175(46.7)$

$109(29.1)$

$121(26.8)$

$186(41.2)$

0.411

$144(31.9)$

$\begin{array}{ccc}202(53.9) & 242(53.7) & 0.999 \\ 1(0,2) & 1(0,2) & 0.029\end{array}$

\section{Q3)}


Treatment interruption during follow-up,
$n(\%)$
$160(19.4)$
$80(21.3)$
$80(17.7)$
0.216
Change in any antiretroviral drug in the
3 months following GRT, $n$ (\%)
$362(43.8)$
$153(40.8)$
209 (46.3)
0.121
Use of a new drug after GRT, $n$ (\%)
$105(12.7)$
41 (10.9)
$64(14.2)$
0.174

GSS: genotypic sensitivity score; GRT: genotypic resistance testing; TAM: thymidine analogue mutations; NRTI: nucleoside reverse transcriptase inhibitor; NNRTI: non-nucleoside reverse transcriptase inhibitor; PI: protease inhibitor. 
Table II. Univariable and multivariable logistic regression: unadjusted and adjusted odds ratios for lack of immune recovery.

\begin{tabular}{|c|c|c|c|c|c|c|}
\hline & Unadjusted & $95 \%$ confidence & & Adjusted & $95 \%$ confidence & \\
\hline & OR & limits & $P$ value & OR & limits & $P$ value \\
\hline Gender & 0.810 & $0.599-1.092$ & 0.169 & 0.826 & $0.589-1.156$ & 0.267 \\
\hline Age (per 5-year increase) & 0.999 & $0.919-1.087$ & 0.988 & 1.009 & $0.990-1.029$ & 0.344 \\
\hline Baseline CD4+ (per 50-cell increase) & 1.086 & $1.054-1.119$ & $<0.0001$ & 1.104 & $1.069-1.142$ & $<0.0001$ \\
\hline Viremia detectability ratio (per 0.1 increase) & 1.129 & $1.083-1.179$ & $<0.0001$ & 1.145 & $1.093-1.202$ & $<0.0001$ \\
\hline Year of genotyping & & & 0.003 & & & 0.0007 \\
\hline 2000 vs. 2003 & 2.107 & $1.368-3.268$ & 0.015 & 2.619 & $1.611-4.300$ & 0.002 \\
\hline 2001 vs. 2003 & 1.547 & $1.080-2.218$ & 0.049 & 1.684 & $1.130-2.515$ & 0.039 \\
\hline 2002 vs. 2003 & 1.295 & $0.890-1.883$ & 0.462 & 1.215 & $0.805-1.829$ & 0.129 \\
\hline PI GSS (per unit increase) & 0.925 & $0.856-0.998$ & 0.046 & 0.990 & $0.884-1.110$ & 0.868 \\
\hline \multicolumn{7}{|l|}{ Treatment interruption during follow-up } \\
\hline Yes vs. no & 1.258 & $0.890-1.776$ & 0.194 & 1.337 & $0.917-1.952$ & 0.131 \\
\hline \multicolumn{7}{|l|}{ Change in any antiretroviral drug in the 3 months } \\
\hline Yes vs. no & 0.798 & $0.890-1.776$ & 0.194 & 0.974 & $0.717-1.323$ & 0.865 \\
\hline \multicolumn{7}{|l|}{ Use of a new drug after GRT } \\
\hline Yes vs. no & 0.742 & $0.486-1.124$ & 0.163 & 0.714 & $0.430-1.175$ & 0.188 \\
\hline
\end{tabular}


L10I

$\begin{array}{lllllll}\text { Yes vs. no } & 1.238 & 0.922-1.661 & 0.157 & 0.981 & 0.668-1.438 & 0.922\end{array}$

I54V

$\begin{array}{lllllll}\text { Yes vs. no } & 1.600 & 1.124-2.288 & 0.009 & 1.366 & 0.826-2.264 & 0.224\end{array}$

V82A

$\begin{array}{lllllll}\text { Yes vs. no } & 1.629 & 1.143-2.331 & 0.007 & 1.148 & 0.712-1.855 & 0.572\end{array}$

T69D

$\begin{array}{lllllll}\text { Yes vs. no } & 1.379 & 0.855-2.232 & 0.187 & 1.195 & 0.713-2.007 & 0.498\end{array}$

A98G

$\begin{array}{lllllll}\text { Yes vs. no } & 1.490 & 0.854-2.625 & 0.161 & 1.517 & 0.838-2.768 & 0.170\end{array}$

M184V

$\begin{array}{lllllll}\text { Yes vs. no } & 1.261 & 0.959-1.661 & 0.097 & 1.311 & 0.972-1.770 & 0.076\end{array}$

GSS: genotypic sensitivity score; GRT: genotypic resistance testing; PI: protease inhibitor. 

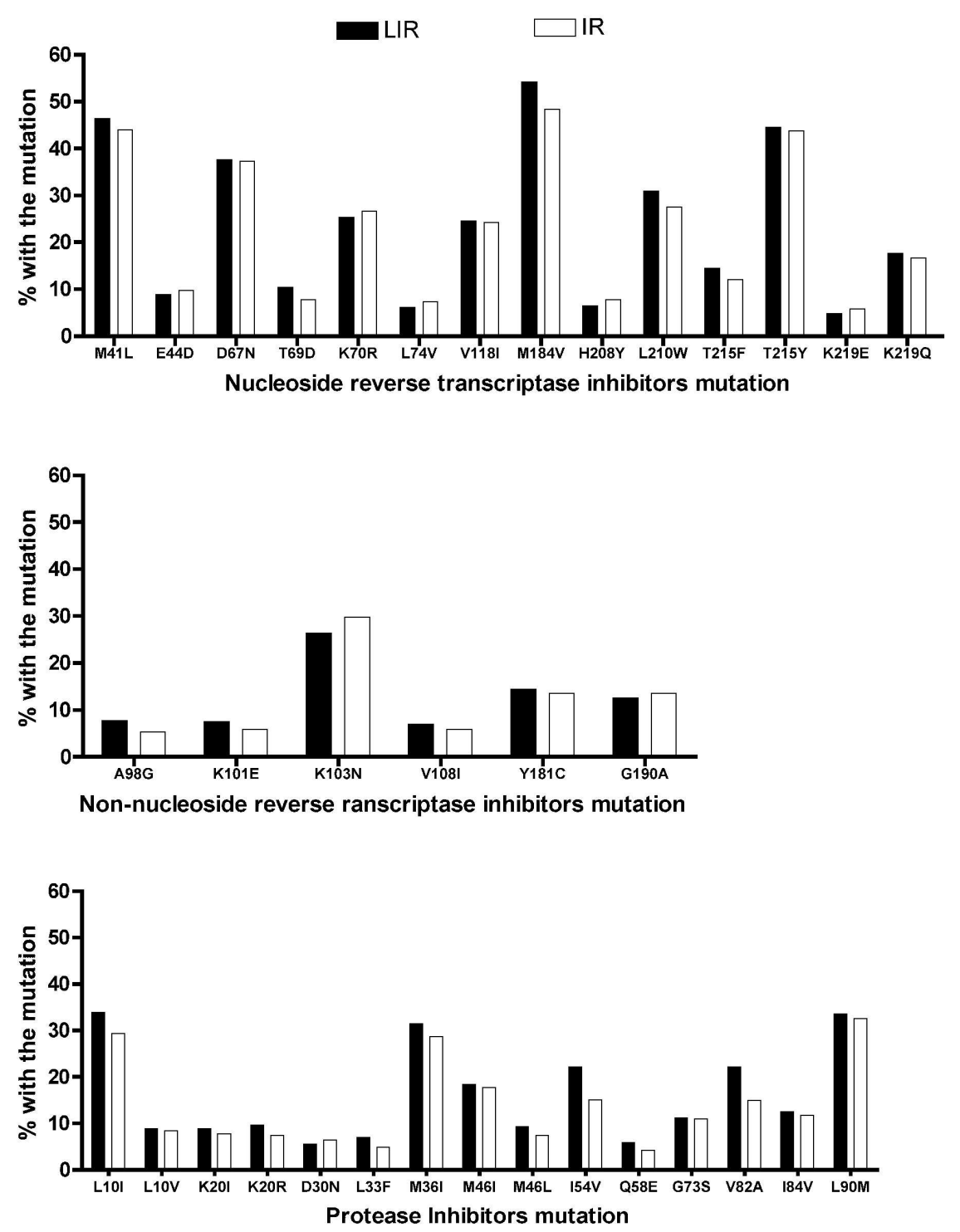

Drug resistance mutations at baseline by antiretroviral class in patients showing immune recovery (IR) or lack of immune recovery (LIR). By univariable analysis, the presence at baseline of the I54V mutation (OR: 1.6 ; 95\% CI: $1.124-2.288$ ) and the V82A mutation (OR: 1.629 ; 95\% CI: $1.143-$ 2.331) was associated with increased odds of lack of immune recovery. $172 \times 214 \mathrm{~mm}(600 \times 600 \mathrm{DPI})$ 


\title{
No pol mutation is associated independently with the lack of immune recovery in patients infected with HIV and failing antiretroviral therapy
}

\begin{abstract}
Nicola Gianotti ${ }^{1 *}$, Laura Galli ${ }^{1}$, Maurizio Zazzi $^{2}$, Valeria Ghisetti $^{3}$, Stefano Bonora $^{4}$, Valeria Micheli ${ }^{5}$, Paola Meraviglia ${ }^{6}$, Paola Corsi $^{7}$, Bianca Bruzzone $^{8}$, Stefano Menzo $^{9}$, Simona Di Giambenedetto ${ }^{10}$, Andrea De Luca ${ }^{10,11}$, Gaetano Filice ${ }^{12}$, Giovanni Penco ${ }^{13}$, Antonella Castagna ${ }^{1}$ on behalf of the ARCA database initiative.
\end{abstract}

${ }^{1}$ Department of Infectious Diseases, IRCCS San Raffaele, Milan, Italy; ${ }^{2}$ Department of Molecular Biology, University of Siena, Siena, Italy; ${ }^{3}$ Microbiology \& Virology Laboratory, Ospedale Amedeo di Savoia, Turin, Italy; ${ }^{4}$ Infectious Diseases Clinic, Ospedale Amedeo di Savoia, Turin, Italy; ${ }^{5}$ Microbiology Laboratory, Ospedale L. Sacco, Milan, Italy; ${ }^{6}$ Second Division of Infectious Diseases, Ospedale L. Sacco, Milan, Italy; ${ }^{7}$ Division of Infectious Diseases, Ospedale Careggi, Florence, Italy; ${ }^{8}$ Health Laboratory, Ospedale San Martino, Genoa, Italy; ${ }^{9}$ Virology Laboratory, Ospedale di Ancona, Ancona, Italy; ${ }^{10}$ Institute of Infectious Diseases, Sacro Cuore Catholic University, Rome, Italy; ${ }^{11}$ Infectious Diseases Unit, University Hospital of Siena, Siena, Italy; ${ }^{12}$ Infectious and Tropical Diseases Clinic, Policlinico San Matteo, Pavia, Italy; ${ }^{13}$ Infectious Diseases, Ospedali Galliera, Genoa, Italy.

Correspondence to:

Dr. Nicola Gianotti

Divisione di Malattie Infettive, Istituto Scientifico San Raffaele

Via Stamira d'Ancona, 20 
20127 - Milano, Italy

Tel.: +390226437906

Fax: +390226437030

E-mail: nicola.gianotti@hsr.it

Running head: HIV-pol mutations and immune recovery (32 characters)

Abstract word count $=238$

Body of the text word count $=1966$ 


\begin{abstract}
An investigation was undertaken to determine whether specific pol mutations hinder long-term immune recovery regardless of virological response. In total, 826 patients with $>50$ HIV RNA copies/mL, who underwent genotypic resistance testing between 1 January 2000 and 31 December 2003 after $>3$ years of antiretroviral treatment, and were followed up for $>3$ years after genotypic resistance testing, were analyzed retrospectively. The outcome of the study was the lack of immune recovery after $>3$ years of follow-up, defined as a slope by linear regression $\leq 0$. The viremia detectability ratio was defined as the number of HIV RNA values of $>50$ copies/mL divided by the number of HIV RNA measurements during follow-up. Logistic regression was used for univariable and multivariable analysis. Median (Q1, Q3) values at baseline were the following: age $40(37,45)$ years, years on antiretroviral therapy $4.45(3.65,5.47)$, HIV RNA $3.91(3.39,4.53) \log _{10}$ copies/mL, CD4+ T-cell $358(211,524) / \mu L$. After 3.13 years of follow-up, 375 patients $(45.4 \%)$ showed a lack of immune recovery. The risk of lack of immune recovery increased independently with increasing baseline CD4+ counts $(\mathrm{OR}=1.104$ per 50 -cell increase, $95 \% \mathrm{CI}=1.069-1.142, \mathrm{p}<0.0001)$, increasing viremia detectability ratio during follow-up $(\mathrm{OR}=1.145$ per 0.1 -unit increase, $95 \% \mathrm{CI}$ $=1.093-1.202, \mathrm{p}<0.0001$ ), and with earlier calendar years of resistance testing (overall effect: $\mathrm{p}=0.0007$ ). In conclusion, no pol mutation is associated independently with the lack of immune recovery.
\end{abstract}

KEY WORDS: CD4+ T-lymphocytes; drug resistance; resistance to protease inhibitors; resistance to nucleoside reverse transcriptase inhibitors; resistance to nonnucleoside reverse transcriptase inhibitors. 


\section{INTRODUCTION}

Extensive antiretroviral resistance is associated with a blunted virological response to subsequent regimens; in particular, there is a gradient of response depending on the number of active drugs, with greater efficacy being found in the patients who receive more active drugs (Hicks et al., 2006; Clotet et al., 2007; Lazzarin et al., 2007; Madruga et al., 2007; Fätkenheuer et al., 2008; Cooper et al., 2008).

It has been shown that extensive resistance to nucleoside reverse transcriptase inhibitors (NRTIs), non-NRTIs (NNRTIs), and protease inhibitors (PIs) increases the risk of progression to AIDS or death (Ormaasen et al., 2004; Hogg et al., 2006; Zaccarelli et al., 2007; Lohse et al., 2007), and that there are associations between clinical progression and single pol mutations (De Luca et al., 2006; Zaccarelli et al., 2007). One possible reason for these findings is that extensive drug resistance and some mutations in particular hamper the virological efficacy of subsequent regimens, thus leading to a weaker immune response and increasing eventually the rate of disease progression. However, this view has been challenged by one study (Lohse et al., 2007) that found mortality to be independent of CD4+ values at the time of death.

The relationship between the degree of drug resistance (or the number of active drugs) and the extent of immune recovery after the failure of an antiretroviral regimen has not been investigated, and it is not known whether specific pol mutations can hinder longterm immune recovery regardless of the virological efficacy of new antiretroviral regimens after drug failure.

This study was aimed at identifying the predictors of a lack of immune recovery in this clinical setting and at investigating whether specific pol mutations or their combinations may be associated independently with hindered immune reconstitution. 


\section{METHODS}

The Antiretroviral Resistance Cohort Analysis (ARCA) database is a public database that has been developed as a means of investigating resistance to antiretroviral drugs, and contains data concerning the patients' treatment, longitudinally collected CD4+ cell counts, plasma HIV-RNA measurements, and HIV sequences. The data are provided by the individual centres, and descriptive statistics can be consulted in the public access area of the database at www.hivarca.net.

For the purposes of this retrospective study, we considered all of the HIV-infected patients in the database with $>50$ HIV RNA copies/ml while on antiretroviral treatment (ART), who underwent genotypic resistance testing (GRT) between 1 January 2000 and 31 December 2003 after at least three years of ART, and who were followed up for at least three years after GRT. The date of the GRT was considered the study baseline, and baseline values were those recorded on the date nearest to the GRT, provided that this was within the 120 days preceding it; the end-of-follow-up values were those closest to three years after GRT.

HIV genotypes were assessed at each centre on the basis of local procedures and checked for consistency upon sequence uploading into the ARCA database, which stores the sequences and automatically extracts the mutations with respect to HIV-1 consensus B using a built-in local alignment script based on ClustalW. PI mutations were defined as major or minor according to the IAS list (Johnson et al., 2009), and thymidine analogue mutations (TAMs) were profiled as previously described (De Luca et al., 2006). Genotypic sensitivity scores (GSSs) were calculated as the number of active drugs according to the ANRS version 18 algorithm 
(http://www.hivfrenchresistance.org/) from among zidovudine, didanosine, stavudine, lamivudine, abacavir, tenofovir, emtricitabine, nevirapine, efavirenz, etravirine, ritonavir, indinavir, nelfinavir, saquinavir/ritonavir, amprenavir/ritonavir, lopinavir/ritonavir, atazanavir/ritonavir, tipranavir/ritonavir, and darunavir/ritonavir.

\section{Statistical analysis}

The continuous variables were described by means of median values and quartiles $(\mathrm{Q} 1$, Q3) or frequencies (\%), as appropriate.

The study outcome was immune recovery, stratified as immune recovery or a lack of immune recovery after at least 3 years of follow-up. All of the available CD4+ values, obtained between baseline and the end of follow-up, were retained and used in the univariable linear regression to estimate the mean change (slope) in CD4+ values within each study patient. Lack of immune recovery was defined as a mean change in CD4+ count during follow-up of $\leq 0$ (slope $\leq 0$ ); conversely, immune recovery was defined as a mean change in CD4+ count during follow-up of $>0$ ( slope $>0$ ). Univariable linear regression was also applied to HIV RNA values.

The viremia detectability ratio was calculated as the number of HIV RNA values of $>50$ copies/mL divided by the number of HIV-RNA values measured during follow-up. The characteristics of the subjects with lack of immune recovery or immune recovery were compared using Wilcoxon's rank-sum test and the chi-square test. Logistic regression was used for the univariable and multivariable analyses to study the associations between the risk (odds ratio) of lack of immune recovery and the demographic, clinical, and genotypic parameters. Univariable logistic regression was used for all of the clinical and demographic characteristics considered in the study and 
the individual pol mutations observed in at least $5 \%$ of the patients. The multivariable model included only those mutations and patient characteristics associated with the lack of immune recovery in the univariable logistic regression at a level of $p<0.2$, with the exception of age and gender, which were retained as fixed covariates. The odds ratios (OR) and corresponding 95\% confidence intervals were calculated to estimate the risk of lack of immune recovery.

All of the statistical tests were two-sided at the $5 \%$ level and were made using SAS Software (release 9.1; SAS Institute).

\section{RESULTS}

A total of 826 patients fulfilled all of the inclusion criteria and entered the study. Table I shows their baseline demographic and clinical characteristics in detail, grouped on the basis of their immune recovery status (lack of immune recovery vs. immune recovery). The drugs used most frequently for genotyping were lamivudine (797; 96.5\%), zidovudine $(782 ; 94.7 \%)$, stavudine $(723 ; 87.5 \%)$, didanosine $(657 ; 79.5 \%)$, indinavir (560; 67.8\%), saquinavir $(479 ; 58.0 \%)$, and nelfinavir $(403 ; 48.8 \%)$. Tenofovir was used more frequently among patients who showed immune recovery in the next three years of follow-up $(\mathrm{p}=0.02)$; statistically significant differences were not observed with regard to other drugs.

Figure 1 illustrates the proportion of patients with individual pol mutations (excluding those observed in fewer than 5\%, which were not considered in the analysis). Fortyseven patients $(5.7 \%)$ had no pol mutations at baseline. 
During follow-up, there was no statistically significant difference in the drugs prescribed, except for atazanavir, which was included more frequently $(p=0.002)$ in the regimens received by patients with immune recovery.

After 3.13 years of follow-up, the overall mean (SE) slope in CD4+ cell count was 7.90 (1.85) cells per year of follow-up (lack of immune recovery: -33.2 (1.67); immune recovery: 42.1 (1.97); $\mathrm{p}<0.0001$ ), and the mean (SE) slope in HIV RNA levels was $0.18(0.01) \log _{10}$ copies/ml per year (lack of immune recovery: -0.06 (0.02); immune recovery: $-0.28(0.01) ; \mathrm{p}<0.0001)$. Overall, 375 patients $(45.4 \%)$ showed lack of immune recovery. The median (Q1, Q3) CD4+ count at the end of follow-up was 377 $(232,561)$ cells/ $\mu \mathrm{L}$ (lack of immune recovery: $322(177,503)$; immune recovery: 411 $(277,613) ; \mathrm{p}<0.0001)$. The virological outcome at the end of follow-up is shown in Table I.

Table II shows the results of the univariable and multivariable logistic regression. By multivariable analysis, the risk of lack of immune recovery increased with increasing baseline CD4+ cell count $(\mathrm{OR}=1.104$ per 50-cell increase, $95 \% \mathrm{CI}=1.069-1.142, \mathrm{p}<$ $0.0001)$ and increasing viremia detectability ratio during follow-up ( $\mathrm{OR}=1.145$ per 0.1 increase, $95 \% \mathrm{CI}=1.093-1.202, \mathrm{p}<0.0001)$. In addition, the odds of lack of immune recovery decreased with decreasing calendar year of genotyping (overall effect: $\mathrm{p}=$ $0.0007)$.

None of the resistance mutations included in the multivariable model resulted in an increase or decrease in the odds of lack of immune recovery. 


\section{DISCUSSION}

If specific pol mutations were able to hinder immune recovery in HIV-infected patients failing antiretroviral therapy, it would be wise (when possible) to avoid the use of drugs selecting preferentially these mutations. The present analysis did not detect any pol mutation that predicted a long-term lack of immune recovery regardless of virological response to the regimens that the patients received after GRT: this implies that, in terms of the risk of lack of immune recovery, there should be no reason to prefer one PI rather than another or one RTI rather than another.

The results of the present study also suggest that, in patients harbouring drug-resistant HIV variants, disease progression is not just a direct consequence of hindered immune recovery following subsequent regimens or of the pol mutations selected at failure, but the result of a complex interplay between various factors (including virological and immunological factors as well as adherence to treatment after GRT).

Immune recovery after treatment failure was predicted independently by the ability of the new regimen(s) to suppress viremia, baseline CD4+ cell counts, and the year of HIV genotyping. These factors seem thus to be more important than individual mutations selected by the failing regimen in driving immune recovery during the next years of therapy.

A gradient of immune responses relating to the degree of virological response was observed previously (Wood et al., 2000). The viremia detectability ratio has been used to measure virological responses to the regimens prescribed after GRT because it was believed that, unlike point observations, this could provide detailed information concerning the cumulative exposure to HIV throughout the follow-up. A positive association between the viremia detectability ratio and lack of immune recovery is also 
consistent with the results of clinical trials showing that virological and immune responses are related directly in treatment-experienced patients (Lalezari et al., 2003; Lazzarin et al., 2003; Hicks et al., 2006; Clotet et al., 2007; Lazzarin et al., 2007; Fätkenheuer et al., 2008; Gulick et al., 2008; Steigbigel et al., 2008). Furthermore, these findings also underline the importance of pursuing the goal of HIV RNA values of $<50$ copies/mL also in this clinical setting (Hammer et al., 2008). The M184V mutation was not associated with immune recovery: one hypothesis it that this mutation slows the CD4+ cell loss as compared to treatment interruption (Castagna et al., 2006), but it does not necessarily favour immune recovery when antiretroviral therapy is continued (Fox et al., 2006).

Year of genotyping was another independent predictor of lack of immune recovery: this likely reflects the improved ability of interpreting genotypic drug-resistance testing and constructing more effective new regimens after treatment failure in more recent years. In addition to those typical of all retrospective analyses, the present study has some specific limitations. Patients who were lost to follow-up or who died during the 3-year follow-up period were excluded from the analysis. It is possible that they had the worst immune response, but this analysis was aimed at studying the association between pol mutations and long-term immune responses rather than the rate of clinical progression. Another limitation is the fact that data concerning adherence to therapy before and after study entry were not uniformly collected: poor adherence is a relevant predictor of lack of immune recovery (Gazzola et al., 2009), and so it is likely that patients with lower viremia detectability ratios were those more adherent to treatment. In conclusion, no pol mutation was associated with a lack of immune recovery in viremic patients who underwent GRT and were followed up for at least three years, 
regardless of the virological outcome of their subsequent regimens. Lack of immune recovery was independently predicted by $\mathrm{CD} 4+$ cell counts at the time of failure of the previous regimen, the viremia detectability ratio during follow-up, and the year of HIV genotyping. Gaining knowledge of the role of these virus- and patient-related factors may help to optimise immune recovery in patients harbouring drug-resistant HIV variants. 
Disclosure of potential conflicts of interest: NG has acted as a consultant to and received research grants from Bristol-Myers Squibb, Abbott, Roche, BoehringerIngelheim, Pfizer, Virco (Johnson \& Johnson), Gilead Sciences, and GlaxoSmithKline. MZ has been a consultant to Abbott Molecular, Gilead Sciences, and Boehringer Ingelheim and has received research support or lecture fees from Abbott Pharmaceuticals, Merck Sharp \& Dome, Pfizer, and Janssen-Cilag. No other author has potential conflicts of interest to declare.

\section{Acknowledgements}

Nicola Gianotti conceived and designed the study, collected and updated data, and wrote the first draft of the manuscript.

Laura Galli designed the study, performed the statistical analyses and interpretations, and wrote the first draft of the manuscript.

(Nicola Gianotti and Laura Galli contributed equally to the writing of this article.) Maurizio Zazzi designed the study, collected and updated data, and contributed to the writing of the manuscript.

Valeria Ghisetti collected and updated data.

Stefano Bonora collected and updated data.

Valeria Micheli collected and updated data.

Paola Meraviglia collected and updated data

Paola Corsi collected and updated data.

Bianca Bruzzone collected and updated data.

Stefano Menzo collected and updated data.

Simona Di Giambenedetto collected and updated data. 
Andrea De Luca collected and updated data.

Gaetano Filice collected and updated data.

Giovanni Penco collected and updated data.

Antonella Castagna designed the study and contributed to the writing of the manuscript.

The following centres currently contribute clinical and laboratory data to the ARCA database initiative. Ancona - Clinica di Malattie Infettive, Andrea Giacometti; Ancona Immunologia Clinica, Luca Butini; Ancona - Malattie Infettive, Romana del Gobbo; Ancona - Virologia, Stefano Menzo; Arezzo - Malattie Infettive, Danilo Tacconi; Ascoli Piceno - Malattie Infettive, Giovanni Corbelli; Aviano - Centro di Riferimento Oncologico, Stefania Zanussi; Bari - Clinica Malattie Infettive, Laura Monno; Bari Virologia, Grazia Punzi; Bergamo - Malattie Infettive, Franco Maggiolo; Bergamo Microbiologia e Virologia, Annapaola Callegaro; Bologna - Malattie Infettive S. Orsola, Leonardo Calza; Bologna - UO Microbiologia, Laboratorio Retrovirus, Maria Carla Re; Bolzano - Malattie Infettive, Raffaele Pristerà; Brescia - Fleming Labs, Paola Turconi; Cagliari - Centro S.I.D.A., Policlinico Universitario, Antonella Mandas; Città di Castello - Medicina Generale, Sauro Tini; Cremona - Malattie Infettive, Giuseppe Carnevale; Cremona - Servizio Immunoematologia e Medcina Trasfusionale, Elisabetta Paolini; Fermo - Malattie Infettive, Giorgio Amadio; Ferrara - Malattie Infettive, AOU S. Anna, Laura Sighinolfi; Firenze - Centro MTS, Giuliano Zuccati; Firenze Ematologia Careggi, Massimo Morfini; Firenze - Immunoallergologia Careggi, Roberto Manetti; Firenze - Malattie Infettive Careggi, Paola Corsi; Firenze - Malattie Infettive Pediatria Meyer, Luisa Galli; Firenze - Malattie Infettive SM Annunziata, Massimo Di Pietro; Firenze - Malattie Infettive, Università, Filippo Bartalesi; Firenze - Virologia 
Careggi, Grazia Colao; Foligno - Malattie Infettive / SERT, Andrea Tosti; Genova -

Clinica Malattie Infettive, AOU S. Martino, Antonio Di Biagio; Genova - Clinica

Medica Immunologia, Maurizio Setti; Genova - Laboratorio di Igiene, Ospedale S.

Martino, Bianca Bruzzone; Genova - Malattie Infettive, Ospedali Galliera, Giovanni

Penco; Grosseto - Malattie Infettive, Michele Trezzi; Lecco - Malattie Infettive, Anna

Orani; Livorno - Malattie Infettive, Riccardo Pardelli; Lucca - Malattie Infettive,

Michele De Gennaro; Macerata - Malattie Infettive, Alessandro Chiodera; Mantova -

Malattie Infettive, Ospedale 'C. Poma', Alfredo Scalzini; Mantova - Virologia,

Loredana Palvarini; Massa - Malattie Infettive, Paolo Almi; Messina - Malattie

Infettive, Giovanni Todaro; Milano HSR - Studio MUSA, Nicola Gianotti; Milano -

Clinica di Malattie Infettive, Ospedale S. Paolo, Paola Cicconi; Milano - Dipart.

Scienze Cliniche, Sez. Malattie Infettive - Università degli Studi, Stefano Rusconi;

Milano - Laboratorio Microbiologia, Ospedale L. Sacco (Dipart. Scienze Cliniche, Sez.

Malattie Infettive), Maria Rita Gismondo; Milano - Laboratorio Microbiologia,

Ospedale L. Sacco (Prima Divisione Malattie Infettive), Maria Rita Gismondo; Milano -

Laboratorio Microbiologia, Ospedale L. Sacco (Seconda Divisione Malattie Infettive),

Valeria Micheli; Milano - Laboratorio di diagnostica molecolare infettivologica, AO S.

Paolo, Maria Luisa Biondi; Milano - Malattie Infettive, San Raffaele, Nicola Gianotti;

Milano - Prima Divisione Malattie Infettive, Ospedale L. Sacco, Amedeo Capetti;

Milano - Seconda Divisione Malattie Infettive, Ospedale L. Sacco, Paola Meraviglia;

Milano - Virologia HSR, Enzo Boeri; Modena - Virologia, Monica Pecorari; Modena -

Malattie Infettive, Cristina Mussini; Narni - SERT, Maurizio Santirocchi; Novara -

Malattie Infettive, AO Maggiore, Diego Brustia; Novara - Virologia, Paolo Ravanini;

Padova - Virologia, Federico Dal Bello; Palermo - Centro Riferimento AIDS, 
Università, Nino Romano; Palermo - Servizio Riferimento Regionale Diagnosi AIDS, Salvatrice Mancuso; Parma - Divisione Malattie Infettive ed Epatologia, Azienda Ospedaliera, Carlo Calzetti; Pavia - Ambulatorio Clinica Malattie Infettive, S. Matteo Renato Maserati; Pavia - Clinica Malattie Infettive e Tropicali, Gaetano Filice; Pavia Virologia, S. Matteo, Fausto Baldanti; Perugia - Malattie Infettive, Daniela Francisci; Pescara - Malattie Infettive, Giustino Parruti; Pescara - Virologia, Ennio Polilli; Piacenza - Malattie Infettive, Daria Sacchini; Pisa - Malattie Infettive, Chiara Martinelli; Pisa - Pediatria I, Università, Rita Consolini; Pisa - Virologia, Linda Vatteroni; Pistoia - Malattie Infettive, Angela Vivarelli; Prato - Malattie Infettive, Alessandro Nerli; Prato - Virologia, Lucia Lenzi; Reggio Emilia - Malattie Infettive, Giacomo Magnani; Rimini - Malattie Infettive, Patrizia Ortolani; Roma - Cattedra Malattie Infettive, Tor Vergata, Massimo Andreoni; Roma - IRCCS S. Gallicano, Guido Palamara; Roma - Immunologia Clinica, Umberto I, Caterina Fimiani; Roma - Istituto Superiore di Sanità, Lucia Palmisano; Roma - Istituto di Clinica Malattie Infettive, Cattolica, Andrea De Luca; Roma - Laboratorio virologia, Cattolica, Simona Di Giambenedetto; Roma - Malattie Infettive, INMI Spallanzani, Andrea Antinori; Roma Malattie Infettive e Tropicali, La Sapienza, Umberto I, Vincenzo Vullo; Roma Medicina Sperimentale e Patologia, Sezione Virologia, La Sapienza, Ombretta Turriziani; Roma - Monitoraggio Terapie Antivirali e Antineoplastiche, INMI Spallanzani, Carlo Federico Perno; Roma - Virologia DMS, Tor Vergata, Carlo Federico Perno; Roma - Virologia Malattie Infettive, Tor Vergata, Marco Montano; Sanremo - Malattie Infettive, Giovanni Cenderello; Siena - Malattie Infettive, Angela Gonnelli; Siena - Virologia, Laura Romano; Terni - Malattie Infettive, Michele Palumbo; Torino - Laboratorio di Virologia, Ospedale Amedeo di Savoia, Valeria 
Ghisetti; Torino - Malattie Infettive, Amedeo di Savoia, Stefano Bonora; Trento -

Malattie Infettive, Palma Delle Foglie; Treviso - Malattie Infettive, Cristina Rossi;

Verbania - Malattie Infettive, Federica Poletti; Verbania - Virologia, Vincenzo

Mondino; Verona - Centro di Medicina Preventiva, ULSS 20, Marina Malena; Verona -

Malattie Infettive, Emanuela Lattuada. 


\section{FIGURE TITLES AND LEGENDS}

Figure 1. Drug resistance mutations at baseline by antiretroviral class in patients showing immune recovery (IR) or lack of immune recovery (LIR). By univariable analysis, the presence at baseline of the I54V mutation (OR: 1.6; 95\% CI: 1.124-2.288) and the V82A mutation (OR: 1.629; 95\% CI: 1.143-2.331) was associated with increased odds of lack of immune recovery. 


\section{REFERENCES}

Castagna A, Danise A, Menzo S, Galli L, Gianotti N, Carini E, Boeri E, Galli A, Cernuschi M, Hasson H, Clementi M, Lazzarin A. 2006. Lamivudine monotherapy in HIV-1-infected patients harbouring a lamivudine-resistant virus: a randomized pilot study (E-184V study). AIDS 20:795-803.

Clotet B, Bellos N, Molina JM, Cooper D, Goffard JC, Lazzarin A, Wöhrmann A, Katlama C, Wilkin T, Haubrich R, Cohen C, Farthing C, Jayaweera D, Markowitz M, Ruane P, Spinosa-Guzman S, Lefebvre E; POWER 1 and 2 study groups. 2007. Efficacy and safety of darunavir-ritonavir at week 48 in treatment-experienced patients with HIV-1 infection in POWER 1 and 2: a pooled subgroup analysis of data from two randomised trials. Lancet 369:1169-78.

Cooper DA, Steigbigel RT, Gatell JM, Rockstroh JK, Katlama C, Yeni P, Lazzarin A, Clotet B, Kumar PN, Eron JE, Schechter M, Markowitz M, Loutfy MR, Lennox JL, Zhao J, Chen J, Ryan DM, Rhodes RR, Killar JA, Gilde LR, Strohmaier KM, Meibohm AR, Miller MD, Hazuda DJ, Nessly ML, DiNubile MJ, Isaacs RD, Teppler H, Nguyen BY; BENCHMRK Study Teams. 2008. Subgroup and resistance analyses of raltegravir for resistant HIV-1 infection. N Engl J Med 359:355-65.

De Luca A, Di Giambenedetto S, Cingolani A, Bacarelli A, Ammassari A, Cauda R. 2006. Three-year clinical outcomes of resistance genotyping and expert advice: extended follow-up of the Argenta trial. Antivir Ther 11:321-7. 
De Luca A, Di Giambenedetto S, Romano L, Gonnelli A, Corsi P, Baldari M, Di Pietro M, Menzo S, Francisci D, Almi P, Zazzi M; Antiretroviral Resistance Cohort Analysis Study Group. 2006. Frequency and treatment-related predictors of thymidine-analogue mutation patterns in HIV-1 isolates after unsuccessful antiretroviral therapy. J Infect Dis 193:1219-22.

Fätkenheuer G, Nelson M, Lazzarin A, Konourina I, Hoepelman AI, Lampiris H, Hirschel B, Tebas P, Raffi F, Trottier B, Bellos N, Saag M, Cooper DA, Westby M, Tawadrous M, Sullivan JF, Ridgway C, Dunne MW, Felstead S, Mayer H, van der Ryst E; MOTIVATE 1 and MOTIVATE 2 Study Teams. 2008. Subgroup analyses of maraviroc in previously treated R5 HIV-1 infection. N Engl J Med 359:1442-55.

Fox Z, Dragsted UB, Gerstoft J, Phillips AN, Kjaer J, Mathiesen L, Youle M, Katlama C, Hill A, Bruun JN, Clumeck N, Dellamonica P, Lundgren JD; COLATE study group. 2006. A randomized trial to evaluate continuation versus discontinuation of lamivudine in individuals failing a lamivudine-containing regimen: the COLATE trial. Antivir Ther 11:761-70.

Gazzola L, Tincati C, Bellistri GM, Monforte A, Marchetti G. 2009. The absence of CD4+ T cell count recovery despite receipt of virologically suppressive highly active antiretroviral therapy: clinical risk, immunological gaps, and therapeutic options. Clin Infect Dis 48:328-37. 
Gulick RM, Lalezari J, Goodrich J, Clumeck N, DeJesus E, Horban A, Nadler J, Clotet

B, Karlsson A, Wohlfeiler M, Montana JB, McHale M, Sullivan J, Ridgway C, Felstead

S, Dunne MW, van der Ryst E, Mayer H; MOTIVATE Study Teams. 2008. Maraviroc

for previously treated patients with R5 HIV-1 infection. N Engl J Med 359:1429-41.

Hammer SM, Eron JJ Jr., Reiss P, Schooley RT, Thompson MA, Walmsley S, Cahn P, Fischl MA, Gatell JM, Hirsch MS, Jacobsen DM, Montaner JS, Richman DD, Yeni PG, Volberding PA; International AIDS Society-USA. 2008. Antiretroviral treatment of adult HIV infection: 2008 recommendations of the International AIDS Society-USA panel. JAMA 300:555-70.

Hicks CB, Cahn P, Cooper DA, Walmsley SL, Katlama C, Clotet B, Lazzarin A, Johnson MA, Neubacher D, Mayers D, Valdez H; RESIST investigator group. 2006. Durable efficacy of tipranavir-ritonavir in combination with an optimised background regimen of antiretroviral drugs for treatment-experienced HIV-1-infected patients at 48 weeks in the Randomized Evaluation of Strategic Intervention in multi-drug reSistant resistant patients with Tipranavir (RESIST) studies: an analysis of combined data from two randomised open-label trials. Lancet 368:466-75.

Hogg RS, Bangsberg DR, Lima VD, Alexander C, Bonner S, Yip B, Wood E, Dong WW, Montaner JS, Harrigan PR. 2006. Emergence of drug resistance is associated with an increased risk of death among patients first starting HAART. PLoS Med 3:e356. 
Johnson VA, Brun-Vezinet F, Clotet B, Gunthard HF, Kuritzkes DR, Pillay D, Schapiro JM, Richman DD. 2009. Update of the drug resistance mutations in HIV-1: December 2009. Top HIV Med 17:138-45

Lalezari JP, Henry K, O'Hearn M, Montaner JS, Piliero PJ, Trottier B, Walmsley S, Cohen C, Kuritzkes DR, Eron JJ Jr, Chung J, DeMasi R, Donatacci L, Drobnes C, Delehanty J, Salgo M; TORO 1 Study Group. 2003. Enfuvirtide, an HIV-1 fusion inhibitor, for drug-resistant HIV infection in North and South America. N Engl J Med $348: 2175-85$.

Lazzarin A, Clotet B, Cooper D, Reynes J, Arastéh K, Nelson M, Katlama C, Stellbrink HJ, Delfraissy JF, Lange J, Huson L, DeMasi R, Wat C, Delehanty J, Drobnes C, Salgo M; TORO 2 Study Group. 2003. Efficacy of enfuvirtide in patients infected with drugresistant HIV-1 in Europe and Australia. N Engl J Med 348:2186-95.

Lazzarin A, Campbell T, Clotet B, Johnson M, Katlama C, Moll A, Towner W, Trottier B, Peeters M, Vingerhoets J, de Smedt G, Baeten B, Beets G, Sinha R, Woodfall B; DUET-2 study group. 2007. Efficacy and safety of TMC125 (etravirine) in treatmentexperienced HIV-1-infected patients in DUET-2: 24-week results from a randomised, double-blind, placebo-controlled trial. Lancet 370:39-48.

Lohse N, Jørgensen LB, Kronborg G, Møller A, Kvinesdal B, Sørensen HT, Obel N, Gerstoft J; Danish HIV Cohort Study. 2007. Genotypic drug resistance and long-term mortality in patients with triple-class antiretroviral drug failure. Antivir Ther 12:909-17. 
Madruga JV, Cahn P, Grinsztejn B, Haubrich R, Lalezari J, Mills A, Pialoux G, Wilkin T, Peeters M, Vingerhoets J, de Smedt G, Leopold L, Trefiglio R, Woodfall B; DUET-1 study group. 2007. Efficacy and safety of TMC125 (etravirine) in treatmentexperienced HIV-1-infected patients in DUET-1: 24-week results from a randomised, double-blind, placebo-controlled trial. Lancet 370:29-38.

Ormaasen V, Sandvik L, Asjø B, Holberg-Petersen M, Gaarder PI, Bruun JN. 2004. An algorithm-based genotypic resistance score is associated with clinical outcome in HIV1-infected adults on antiretroviral therapy. HIV Med 5:400-6.

Steigbigel RT, Cooper DA, Kumar PN, Eron JE, Schechter M, Markowitz M, Loutfy MR, Lennox JL, Gatell JM, Rockstroh JK, Katlama C, Yeni P, Lazzarin A, Clotet B, Zhao J, Chen J, Ryan DM, Rhodes RR, Killar JA, Gilde LR, Strohmaier KM, Meibohm AR, Miller MD, Hazuda DJ, Nessly ML, DiNubile MJ, Isaacs RD, Nguyen BY, Teppler H; BENCHMRK Study Teams. 2008. Raltegravir with optimized background therapy for resistant HIV-1 infection. N Engl J Med 359:339-54.

Wood E, Yip B, Hogg RS, Sherlock CH, Jahnke N, Harrigan RP, O'Shaughnessy MV, Montaner JS. 2000. Full suppression of viral load is needed to achieve an optimal CD4 cell count response among patients on triple drug antiretroviral therapy. AIDS 14:195560. 
Zaccarelli M, Tozzi V, Lorenzini P, Forbici F, Narciso P, Ceccherini-Silberstein F, Trotta MP, Bertoli A, Liuzzi G, Marconi P, Mosti S, Perno CF, Antinori A. 2007. The V118I mutation as a marker of advanced HIV infection and disease progression. Antivir Ther 12:163-8.

Zaccarelli M, Forbici F, Lorenzini P, Ceccherini-Silberstein F, Tozzi V, Trotta MP, Marconi P, Pasquale N, Perno CF, Antinori A. 2007. Continuous evidence of fast HIV disease progression related to class-wide resistance to antiretroviral drugs: a 6 year follow-up analysis of a large observational database. AIDS 21:1824-6. 